\title{
Degradabilidade do Bagaço de Cana-de-Açúcar Tratado com Amônia Anidra e, ou, Sulfeto de Sódio ${ }^{1}$
}

\author{
Aureliano José Vieira Pires ${ }^{2}$, Rasmo Garcia $^{3}$, Sebastião de Campos Valadares Filho ${ }^{3}$, Odilon \\ Gomes Pereira ${ }^{3}$, Paulo Roberto Cecon ${ }^{4}$, Fabiano Ferreira da Silva ${ }^{5}$, Polyana Albino Silva ${ }^{6}$, \\ Luís Carlos Vinhas Ítavo ${ }^{7}$
}

\begin{abstract}
RESUMO - Foram utilizados três novilhos Holandeses, canulados no rúmen, mantidos em confinamento, em baias individuais, nos quais foram incubados sacos de náilon contendo bagaço de cana-de-açúcar, conforme os seguintes tratamentos: T1 - Bagaço sem tratamento (controle); T2 - Bagaço tratado com 2,5\% de $\mathrm{Na}_{2} \mathrm{~S}$; T3 - Bagaço tratado com $4 \%$ de $\mathrm{NH}_{3}$ e T4 - Bagaço tratado com 2,5\% de $\mathrm{Na}_{2} \mathrm{~S}+4 \%$ de $\mathrm{NH}_{3}$. Verificou-se maior degradabilidade potencial para o bagaço tratado com $\mathrm{NH}_{3}$ e com $\mathrm{NH}_{3}$ mais $\mathrm{Na}_{2} \mathrm{~S}$. A degradabilidade da matéria seca (DMS) variou de 38,3 a 65,5\%, do controle para o bagaço tratado com amônia anidra após período de incubação de 96 horas. Verificaram-se, para a degradabilidade da fibra em detergente neutro, maiores valores da fração potencialmente degradável “b” e menores da fração indigerível "I" para o bagaço tratado com $\mathrm{NH}_{3}$, independentemente do sulfeto. Para a degradabilidade da FDA, foi observado efeito semelhante ao da degradabilidade da FDN, onde maiores valores da fração potencialmente degradável "b” e menores da fração indigerível "I" foram também verificados para o bagaço tratado com $\mathrm{NH}_{3}$, independentemente do sulfeto. Maiores valores da degradabilidade efetiva foram verificados para o bagaço tratado com $\mathrm{NH}_{3}$ e $\mathrm{Na}_{2} \mathrm{~S}_{\text {mais }} \mathrm{NH}_{3}$, quando comparados ao controle e $\mathrm{Na}_{2} \mathrm{~S}$, que apresentaram comportamentos semelhantes e menores.
\end{abstract}

Palavras-chave: amonização, anidra, bagaço, resíduo

\section{Degradability of Sugarcane Bagasse Treated with Anhydrous Ammonia and/or Sodium Sulfate}

ABSTRACT - Three Holstein steers, canulated in the rumen, where were incubated nylon bags with sugarcane bagasse, were maintained in feedlot, in individual boxes, according to the following treatments: T1 - bagasse without treatment (control); T2 - bagasse treated with $2.5 \% \mathrm{Na}_{2} \mathrm{~S}$; $\mathrm{T} 3$ - bagasse treated with $4 \% \mathrm{NH}_{3}$ and $\mathrm{T} 4$ - bagasse treated with $2.5 \% \mathrm{Na}_{2} \mathrm{~S}+4 \% \mathrm{NH}_{3}$. Higher potential degradability was observed for the treatment with bagasse treated with $\mathrm{NH}_{3}$ and $\mathrm{NH}_{3}$ plus $\mathrm{Na}_{2} \mathrm{~S}$. Dry matter degradability ranged from 38.3 to $65.5 \%$, in the control for the treatment with bagasse treated with anhydrous ammonia after 96 -h incubation. It were observed higher values of potentially degradable "b" fraction for the neutral detergent fiber and smaller values of indigestible "I" fraction for the treatment with bagasse treated with $\mathrm{NH}_{3}$, independently of sulfate. Effect similar to the NDF degradability was observed for the ADF degradability, where higher values of potentially degradable "b" fraction smaller values of indigestible "I" fraction were also observed for the treatment with bagasse treated with $\mathrm{NH}_{3}$, independently of sulfate. Higher values of effective degradability were observed for the treatment with bagasse treated with $\mathrm{NH}_{3}$ and $\mathrm{Na}_{2} \mathrm{~S}$ plus $\mathrm{NH}_{3}$, when compared to control and $\mathrm{Na}_{2} \mathrm{~S}$, that showed similar and smaller results.

Key Words: ammoniation, anhydrous, bagasse, residue

\section{Introdução}

A estimativa da degradabilidade de forragens amonizadas éconsiderada de suma importância, quando se pretende avaliar a eficiência da amonização. Tendo em vista que a degradação e o consumo de forragens, geralmente, estão diretamente correlacionados, 0 conhecimento da extensão da degradabilidade de forragens submetidas à amonização permite a esti- mativa da ingestão voluntária desses alimentos pelos ruminantes (Paiva et al., 1995).

A maioria dos trabalhos sobre amonização de volumosos de baixa qualidade tem mostrado que esse tipo de tratamento promove aumento das degradabilidades da matéria seca e dos constituintes da parede celular destas forragens.

Estudando o efeito da celulose cristalina e a retenção de água em palha de cevada submetida ao

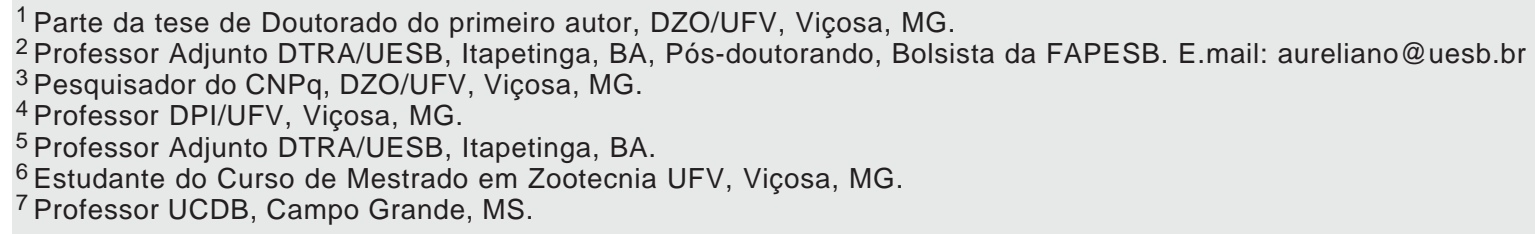


tratamento com 3\% de amônia anidra (base MS), Goto \& Yokoe (1996) relataram que a amonização possui dois efeitos para o aumento da degradabilidade do material tratado. O primeiro, relacionado ao fato de a amônia ser um alcali, limita-se à quebra das ligações éster interpolímeros. Isto resulta em afrouxamento na estrutura da parede celular, que é observado por maior grau de hidratação da parede. O segundo, referente à habilidade da amônia formar complexo com a celulose, reduz, então, sua cristalinidade. Embora esta redução tenha também influenciado a taxa de digestão enzimática, o efeito mais importante deve ser a fragilidade da estrutura.

Ao submeterem palhadas de arroz ao tratamento com doses de 0, 3 e 4\% de uréia (base MS), Rahal et al. (1997) verificaram valores para degradabilidade da matéria orgânica na ordem de $58,1 \%$ para o material sem tratamento e 66,4 e $67,2 \%$, respectivamente, para as doses de 3 e $4 \%$ de uréia, não havendo diferenças entre as doses de uréia.

Paiva et al. (1995), ao utilizarem doses de 0, 2 e $4 \%$ de amônia anidra, em combinação com períodos de amonização de 7, 21 e 35 dias, no tratamento de palhada de milho, determinaram a degradabilidade da matéria seca (DMS), degradabilidade da fibra em detergente neutro (DFDN) e a degradabilidade da fibra em detergente ácido (DFDA), incubando amostras em sacos de náilon por 48 horas. Observaram valores médios de 39,0; 47,0; e 52,3\% para DMS, 35,$7 ; 44,9$; e 50,4\% para DFDN e 40,0; 49,6; e 53,2\% para DFDA, para as doses de 0,2 e $4 \%$ de amônia anidra, respectivamente. Os autores encontraram correlações positivas e altas entre os valores de DMS e DFDN ( $r=0,99)$ e de DFDA ( $r=0,96)$, constatando que, na avaliação da degradabilidade da palhada de milho amonizada, a determinação da DMS é suficiente para estimar o efeito da amônia anidra sobre a degradação dos constituintes da parede celular.

Castrillo et al. (1995), em um experimento com ovinos alimentados com palha de cevada sem tratamento ou tratada com amônia anidra (3\% base MS), verificaram aumentos na digestibilidade da MS (41,6 para 50,2\%) e na DFDN (49,4 para 61,1\%).

Neiva et al. (1998), utilizando carneiros alimentados com dietas à base de silagens de milho e rolão de milho amonizados ou não, relataram que não houve diferenças para consumo de matéria seca (CMS). Para a degradabilidade aparente da matéria seca (DAMS), esses autores verificaram que as silagens amonizadas apresentaram valores superiores
(60,89\%) aos das não-amonizadas (58,09\%). Já para o rolão de milho, não foram observadas diferenças na DAMS. Todavia, a degradabilidade aparente da FDN foi superior em todos materiais amonizados (64,90\%), quando comparados aos não-amonizados (54,33\%).

Djibrillou et al. (1998) relataram que, apesar de os constituintes da parede celular do material tratado com uréia ( 5 kg de uréia em 50 L de água para 100 kg de palha) e do não-tratado não diferirem, a DIVMS variou de 53,1 a $45,4 \%$, respectivamente.

O sulfeto de sódio é usado para produção de polpa de celulose, juntamente com o $\mathrm{NaOH}$, na proporção de 75:25 ( $\mathrm{NaOH}: \mathrm{Na}_{2} \mathrm{~S}$ ), utilizando-se, desta mistura, $15 \%$ com base no peso seco da madeira. Este processo ocorre sob temperatura que varia de 150 a $170^{\circ} \mathrm{C}$, pressão de 4,5 a 6,8 kgf/cm² e período em torno de 2,5 horas. Este procedimento é realizado, geralmente, em eucalipto, que apresenta, em média, 54\% de celulose, 16\% de hemicelulose e 25\% de lignina; após o tratamento, são verificados valores de $2 \%$ lignina.

Fahmy \& Klopfenstein (1994) utilizaram silagem de milho contendo $40 \%$ de MS, em três tratamentos: 1) silagem de milho, 2) silagem de milho com $6,6 \%$ de uréia e 3) silagem de milho com 6,6\% de uréia mais $5 \%$ de $\mathrm{SO}_{2}$ em forma gasosa. Os teores de proteína encontrados para os tratamentos 1, 2 e 3 foram de 5,2; 13,4 ; e $17,1 \%$, respectivamente. Verificaram-se, portanto, aumentos de 156,3 e 226,7\% para os tratamentos com uréia e uréia mais $\mathrm{SO}_{2}$, quando comparados ao controle, o que comprova a eficiência da adição de enxofre na retenção de nitrogênio, quando forragens são tratadas com fontes de nitrogênio não-protéico.

O objetivo do trabalho foi avaliar a degradabilidade da matéria seca e dos constituintes da parede celular do bagaço de cana-de-açúcar tratado com amônia e, ou, sulfeto de sódio.

\section{Material e Métodos}

O experimento foi conduzido na Fazenda Córrego Novo, na cidade de Santa Cruz do Escalvado, e no Departamento de Zootecnia da Universidade Federal de Viçosa, Minas Gerais.

Três silos de superfície com cerca de quatro toneladas de bagaço de cana-de-açúcar contendo 50\% de MS foram confeccionados, utilizando-se lona plástica no solo e na cobertura dos silos. Todos os tratamentos foram feitos com base na matéria seca do bagaço de cana-de-açúcar; para o tratamento com $\mathrm{Na}_{2} \mathrm{~S}$, este foi diluído na proporção de 3:1 água:produto. 
Para aplicação da amônia anidra, utilizou-se um botijão com capacidade de 80 kg de amônia; a quantidade necessária a ser adicionada foi obtida por diferença de peso do botijão, à medida que se aplicava a amônia. A amônia anidra foi aplicada em dois pontos opostos de cada silo, de maneira que permitisse melhor difusão em todo o material ensilado. Utilizaram-se canos PVC de $1 / 2$ " perfurados a cada $20 \mathrm{~cm}$, com diâmetro de $0,5 \mathrm{~cm}$, tendo uma de suas extremidades vedadas.

O bagaço de cana-de-açúcar ficou armazenado por 10 meses e, após a abertura dos silos, amostras foram coletadas conforme tratamentos: T1 - Bagaço sem tratamento (armazenado em local coberto); T2 Bagaço tratado com 2,5\% de $\mathrm{Na}_{2} \mathrm{~S} ; \mathrm{T} 3$ - Bagaço tratado com $4 \%$ de $\mathrm{NH}_{3}$ e T4 - Bagaço tratado com 2,5\% de $\mathrm{Na}_{2} \mathrm{~S}+4 \%$ de $\mathrm{NH}_{3}$.

Foram utilizados três novilhos Holandeses, canulados no rúmen, mantidos em regime de confinamento, em baias individuais, e alimentados, durante o ensaio, com dieta constituída de capimelefante (Pennisetum purpureum Shum.), fornecido ad libitum, e $3 \mathrm{~kg}$ de concentrado à base de milho, farelo de soja e mistura mineral.

As amostras do bagaço de cana-de-açúcar foram moídas em peneiras com crivos de 4 mm e colocadas em sacos de náilon na quantidade de, aproximadamente, 3,0 g de MS/saco, a fim de manter uma relação próxima de $20 \mathrm{mg}$ de $\mathrm{MS} / \mathrm{cm}^{2}$ de área superficial do saco. Os períodos de incubação corresponderam aos tempos de $0,6,12,24,36,48,72$ e 96 horas, sendo os sacos colocados em tempos diferentes e em duplicatas, para serem retirados todos ao mesmo tempo, promovendo, dessa forma, lavagem uniforme do material por ocasião da retirada do rúmen.

Após o período de incubação total de 96 horas, os sacos de náilon foram lavados em água corrente até que esta se apresentasse limpa, procedendo-se, então, à secagem. A determinação da matéria seca (MS) foi feita em estufa a $65^{\circ} \mathrm{C}$, por 72 horas, utilizando as amostras para análises da fibra em detergente neutro (FDN) e fibra em detergente ácido (FDA), segundo metodologia descrita por Silva (1990).

Os dados de degradabilidade in situ da matéria seca (DISMS), FDN (DISFDN) e FDA (DISFDA) foram obtidos pela diferença de peso, encontrada para cada componente, entre as pesagens efetuadas antes e após a incubação ruminal e expressos em porcentagem. Foi utilizado o modelo de Ørskov \&
McDonald (1979) para a degradabilidade potencial da matéria seca de cada tratamento, de acordo com a fórmula: $p=a+b\left(1-e^{-c t}\right)$, em que “p” é degradabilidade potencial; "a”, fração solúvel em água, "b” fração insolúvel em água mas potencialmente degradável; e “c”, taxa de degradação da fração "b”. Para a fração fibrosa (FDN e FDA), foi utilizado o modelo de Mertens (1976), de acordo com a fórmula: $\hat{Y}=b \times e^{(-c \times(T-L))}+I$, em que "Y" é o resíduo no tempo T; "b”, a fração potencialmente degradável da fibra; “c”, a taxa de degradação de b; “T”, o período de incubação em horas; "L”, a latência; e "I”, a fração indigestível da fibra.

A degradabilidade efetiva ou real do bagaço de cana-de-açúcar foi calculada pela fórmula:

$$
p=a+(b \times c) /(c+k)
$$

em que " $k$ " é a taxa de passagem (Ørskov \& McDonald, 1979).

Utilizaram-se as taxas de passagem de 2 e $5 \%$, para o cálculo da degradabilidade efetiva, sendo estes valores relacionados a animais em mantença e ganho de peso, respectivamente.

\section{Resultados e Discussão}

A degradabilidade potencial da matéria seca variou de 38,3 a 65,5\%, após período de incubação de 96 horas, respectivamente, para o controle e o bagaço tratado com $\mathrm{NH}_{3}$.

Na Tabela 1, pode-se observar que a utilização de $\mathrm{NH}_{3}$ aumentou a fração solúvel "a” do material amonizado, apresentando valores de 1,0 e 4,47, para os tratamentos controle e $\mathrm{Na}_{2} \mathrm{~S}$, e 15,74 e 14,50, para os tratamentos com $\mathrm{NH}_{3}$ e com $\mathrm{NH}_{3}$ mais $\mathrm{Na}_{2} \mathrm{~S}$. Para a fração insolúvel, mas potencialmente degradável, "b" apresentou também menores valores para os tratamentos controle e $\mathrm{Na}_{2} \mathrm{~S}(40,85$ e 44,74) e maiores para os tratamentos com $\mathrm{NH}_{3}$ e com $\mathrm{NH}_{3}$ mais $\mathrm{Na}_{2} \mathrm{~S}$ (53,26 e 48,81), respectivamente.

Nota-se que a fração "b” para o material tratado apenas com $\mathrm{NH}_{3}$ foi mais elevada, quando comparada ao tratamento com $\mathrm{NH}_{3}$ mais $\mathrm{Na}_{2} \mathrm{~S}$, o que não era esperado, uma vez que a presença do $\mathrm{Na}_{2} \mathrm{~S}$ em ambiente alcalino poderia aumentar a digestibilidade, em função de possível redução da lignina. Dessa forma, verificou-se que o sulfeto não apresentou qualquer vantagem no tratamento do bagaço de canade-açúcar para o nível estudado.

Cañeque et al. (1998), trabalhando com palha de cevada contendo $40 \%$ de umidade e tratada com $6 \%$

\section{R. Bras. Zootec., v.33, n.4, p.1071-1077, 2004}


de uréia (base MS), avaliaram a degradabilidade da matéria seca, e verificaram para as frações "a", "b" e "c" valores de 20,23 e 23,78\% para "a", de 60,82 e $63,41 \%$ para "b" e de 1,95 e 3,31\% para "c", respectivamente, para a palha sem tratamento e tratada com uréia. Paiva et al. (1995) encontraram valores médios de 39,$0 ; 47,0$; e 52,3\% para DMS, ao utilizarem doses de 0,2 e $4 \%$ de amônia anidra, respectivamente, em palhada de milho, incubando amostras em sacos de náilon por 48 horas.

Aumento na degradabilidade da matéria orgânica foi observado por Rahal et al. (1997), ao tratarem sete variedades de palha de arroz com doses de 0,3 e $4 \%$ de uréia (base MS). Os autores verificaram valores de $58,1 \%$ para o material sem tratamento e 66,4 e $67,2 \%$, respectivamente, para as doses de 3 e $4 \%$ de uréia, não havendo diferenças entre as doses de uréia. Ao compararem palha de arroz sem tratamento e tratada com $3 \%$ de uréia, esses autores encontraram os respectivos valores de 15,8 e 24,4 para a fração "a", de 38,7 e 40,2 para a fração "b" e de 2,47 e 3,11 para a taxa de degradação da fração "b" para uma mesma variedade de arroz, enquanto outra variedade apresentou os respectivos valores de 17,1 e 32,5 para a fração "a", de 33,6 e 31,1 para a fração "b" e de 2,67 e 2,26 para a taxa de degradação de "b" com o mesmo tratamento com 3\% de uréia. Esses resultados mostram a grande variação para valores de frações solúvel e insolúvel e taxa de degradação, de forragens amonizadas.

Bem Salem et al. (1994) verificaram aumento na degradabilidade in situ da matéria seca (DMS) da palhada de sorgo amonizada com uréia $(5,3 \%$ base MS) ou amônia anidra ( $3 \%$ base MS). Os valores encontrados foram de 51,$4 ; 58,3$; e $67,7 \%$ de DMS para a palhada sem tratamento, tratada com uréia e tratada com amônia anidra, respectivamente.

Na Tabela 2, pode-se observar comportamento semelhante para a FDN residual, para o bagaço de cana-de-açúcar não-tratado (controle) e tratado com $\mathrm{Na}_{2} \mathrm{~S}$, bem como para o tratado com $\mathrm{NH}_{3}$ e $\mathrm{NH}_{3}$ mais $\mathrm{Na}_{2} \mathrm{~S}$. Maiores valores da fração potencialmente degradável "b" e menores valores da fração indigerível "I" foram verificados para o bagaço tratado com $\mathrm{NH}_{3}$, independentemente do sulfeto de sódio, 44,03; 41,$06 ; 51,64 ;$ e $53,43 \%$ para "b" e 51,56; 49,79; 34,07; e $34,49 \%$ para "I", respectivamente, para os tratamentos controle, $\mathrm{Na}_{2} \mathrm{~S}, \mathrm{NH}_{3}$ e $\mathrm{NH}_{3}$ mais $\mathrm{Na}_{2} \mathrm{~S}$. Verificou-se, portanto, a eficiência da amônia anidra no aumento da degradabilidade da fibra em detergente neutro para o bagaço de cana-de-açúcar tratado com $\mathrm{NH}_{3}$, independentemente do sulfeto de sódio.

Brown \& Pate (1997), utilizando 4\% de amônia anidra (base MS) em feno de grama estrela armazenado de 42 a 60 dias, encontraram valores médios para o controle e o material amonizado de 40,9 para

Tabela 1 - Equações ajustadas para a degradabilidade da matéria seca (DMS) do bagaço de cana-de-açúcar não-tratado (controle) e tratado com amônia anidra $\left(\mathrm{NH}_{3}\right)$ e, ou, sulfeto de sódio $\left(\mathrm{Na}_{2} \mathrm{~S}\right)$, em função do período de incubação (horas)

Table 1 - Equations adjusted for degradability of the dry matter (DMD) of the sugarcane bagasse not treated (control) and treated with ammonia anhydrous $\left(\mathrm{NH}_{3}\right)$ and, or, sodium sulphide $\left(\mathrm{Na}_{2} \mathrm{~S}\right)$, in function of incubation period (hours)

\begin{tabular}{lcc}
\hline $\begin{array}{l}\text { Tratamento } \\
\text { Treatment }\end{array}$ & \multicolumn{1}{c}{$\begin{array}{c}\text { Equações ajustadas } \\
\text { Adjusted equations }\end{array}$} & $\mathrm{R}^{2}$ \\
\hline $\begin{array}{l}\text { Controle } \\
\text { Control }\end{array}$ & $\hat{\mathrm{Y}}=\mathrm{p}=1,00+40,85 \times\left(1-\mathrm{e}^{-0,0254 \mathrm{t}}\right)$ & 99,26 \\
$\mathrm{Na}_{2} \mathrm{~S}$ & $\hat{\mathrm{Y}}=\mathrm{p}=4,47+44,74 \times\left(1-\mathrm{e}^{-0,0206 \mathrm{t}}\right)$ & 99,66 \\
$\mathrm{NH}_{3}$ & $\hat{\mathrm{Y}}=\mathrm{p}=15,74+53,26 \times\left(1-\mathrm{e}^{-0,0283 \mathrm{t}}\right)$ & 99,04 \\
$\mathrm{Na}_{2} \mathrm{~S}+\mathrm{NH}_{3}$ & $\hat{\mathrm{Y}}=\mathrm{p}=14,50+48,81 \times\left(1-\mathrm{e}^{-0,0234 \mathrm{t}}\right)$ & 99,66 \\
\hline
\end{tabular}

$p=a+b \times\left(1-e^{-c t}\right)$, em que "p" é a degradabilidade potencial; "a", a fração solúvel em água, "b", a fração insolúvel em água mas potencialmente degradável; e "c", a taxa de degradação da fração " $b$ ".

$p=a+b \times\left(1-e^{-c t}\right)$, in that " $p$ " is the potential degradability; "a", the soluble fraction in water, " $b$ ", the insoluble fraction in water but potentially degradable; and "c", the rate of degradation of the fraction " $b$ ". 
58,8\% para DFDN e 28,8 para 49,0\% para DFDA, respectivamente.

Estes resultados confirmam relatos da literatura, em geral, afirmando que em volumosos amonizados ocorre solubilização parcial da hemicelulose e afrouxamento da parede celular, permitindo, dessa forma, que os microrganismos do rúmen tenham maior superfície específica para se agregarem e, conseqüentemente, aumentarem a digestibilidade.

Rahal et al. (1997) encontraram valores diferentes para a fração solúvel (a), a fração insolúvel, mas potencialmente degradável (b), e a taxa de degradação, para a palha de arroz de determinada variedade estudada, 7,5 e 11,5; 43,7 e 45,0; e 2,53 e 3,24 para a fração "a”, fração "b” e taxa de degradação “c”, respectivamente.

Para a degradabilidade da FDA (Tabela 3), efeito semelhante ao da degradabilidade da FDN foi observado. Maiores valores da fração potencialmente degradável "b” e menores valores da fração indigerível "I" foram também verificados para o bagaço tratado com $\mathrm{NH}_{3}$, independentemente do sulfeto, em que os valores encontrados foram de 42,64; 47,78; 57,35; e 57,33\% para “b” e 52,84; 46,51; 32,66; e 35,08\% para "I”, respectivamente, para os tratamentos controle, $\mathrm{NH}_{3}, \mathrm{Na}_{2} \mathrm{~S}$ e $\mathrm{NH}_{3}$ mais $\mathrm{Na}_{2} \mathrm{~S}$. Dessa forma, pode-se verificar a eficiência da amônia anidra no tratamento de volumosos de baixa qualidade, promovendo aumento da degradabilidade nas frações fibrosas, independentemente do sulfeto de sódio.

Resultados semelhantes foram relatados por Paiva et al. (1995), os quais observaram valores médios de 40,0; 49,6; e 53,2\% para DFDA, para as doses de 0 , 2 e $4 \%$ de amônia anidra, respectivamente. Os autores encontraram, ainda, correlações positivas e altas entre os valores de DMS e DFDN $(r=0,99)$ e DFDA $(r=0,96)$, afirmando, com base nos resultados, que, na avaliação da degradabilidade da palhada de milho amonizada, a determinação da DMS é suficiente para estimar o efeito da amônia anidra sobre a degradação dos constituintes da parede celular.

Avaliando também a degradabilidade da FDA e da FDN, Cañeque et. al. (1998) verificaram valores de 75,12 e $83,72 \%$ para a fração "b" e de 2,24 e 3,99\%/h para "c" da FDA e valores de 75,71 e $83,10 \%$ para "b" e de 2,09 e 3,31\%/h para FDN, respectivamente, para a palha de cevada sem tratamento e tratada com $6 \%$ de uréia (base MS).

Constam, na Tabela 4, os valores para degradabilidade efetiva da matéria seca (DEMS), fibra detergente neutro (DEFDN) e fibra em detergente ácido (DEFDA) do bagaço de cana-de-açúcar sem tratamento, tratado com $\mathrm{NH}_{3}$, tratado com $\mathrm{Na}_{2} \mathrm{~S}$ e tratado com $\mathrm{NH}_{3}$ mais $\mathrm{Na}_{2} \mathrm{~S}$ para as taxas de passagem de 2 e $5 \%$.

Maiores valores para as degradabilidades efetivas

Tabela 2 - Equações ajustadas para a fibra em detergente neutro (FDN) residual do bagaço de cana-de-açúcar não-tratado (controle) e tratado com amônia anidra $\left(\mathrm{NH}_{3}\right)$ e, ou, sulfeto de sódio $\left(\mathrm{Na}_{2} \mathrm{~S}\right)$, em função do período de incubação (horas)

Table 2 - Equations adjusted for neutral detergent fiber (NDF) residual of the sugarcane bagasse no treated (control) and treated with ammonia anhydrous $\left(\mathrm{NH}_{3}\right)$ and, or, sodium sulphide $\left(\mathrm{Na}_{2} \mathrm{~S}\right)$, in function of incubation period (hours)

\begin{tabular}{lcc}
\hline $\begin{array}{l}\text { Tratamento } \\
\text { Treatment }\end{array}$ & \multicolumn{1}{c}{$\begin{array}{c}\text { Equações ajustadas } \\
\text { Adjusted equations }\end{array}$} & $\mathrm{R}^{2}$ \\
\hline $\begin{array}{l}\text { Controle } \\
\text { Control }\end{array}$ & $\hat{\mathrm{Y}}=44,03 \times \mathrm{e}^{(-0,0233 \times(\mathrm{T}-4,17))}+51,56$ & 98,52 \\
$\mathrm{Na}_{2} \mathrm{~S}$ & $\hat{\mathrm{Y}}=41,06 \times \mathrm{e}^{(-0,0227 \times(\mathrm{T}-6,65))}+49,79$ & 98,63 \\
$\mathrm{NH}_{3}$ & $\hat{\mathrm{Y}}=51,64 \times \mathrm{e}(-0,0273 \times(\mathrm{T}-8,15))+34,07$ & 97,72 \\
$\mathrm{Na}_{2} \mathrm{~S}+\mathrm{NH}_{3}$ & $\hat{\mathrm{Y}}=53,43 \times \mathrm{e}^{(-0,0230 \times(\mathrm{T}-8,16))}+34,49$ & 99,72 \\
\hline
\end{tabular}

$\overline{\hat{Y}}=b \times e^{(-c \times} \times(T-L)+I$, em que " $\hat{Y}$ " é o resíduo no tempo $T ;$; "b", a fração potencialmente degradável da fibra; "c", a taxa de degradação de b; "T", o período de incubação em horas; "L", a latência; e "I", a fração indigestível da fibra.

$\hat{Y}=b \times e^{(-c \times(T-L)}+l$, in that " $Y$ " is the residue in the time $T$; " $b "$, the fraction potentially degradable of fiber " $c$ ", rate of degradation of " $b$ "; " $T$ ", the incubation period in hours; " $L$ ", the latency; and "I", fraction indigestible of fiber.

R. Bras. Zootec., v.33, n.4, p.1071-1077, 2004 
Tabela 3 - Equações ajustadas para a fibra em detergente ácido (FDA) residual do bagaço de cana-de-açúcar não-tratado (controle) e tratado com amônia anidra $\left(\mathrm{NH}_{3}\right)$ e, ou, sulfeto de sódio $\left(\mathrm{Na}_{2} \mathrm{~S}\right)$, em função do período de incubação (horas)

Table 3 - Equations adjusted for acid detergent fiber (ADF) residual of the sugarcane bagasse no treated (control) and treated with ammonia anhydrous $\left(\mathrm{NH}_{3}\right)$ and, or, sodium sulphide $\left(\mathrm{Na}_{2} \mathrm{~S}\right)$, in function of incubation period (hours)

\begin{tabular}{lcc}
$\begin{array}{l}\text { Tratamento } \\
\text { Treatment }\end{array}$ & \multicolumn{1}{c}{$\begin{array}{c}\text { Equações ajustadas } \\
\text { Adjusted equations }\end{array}$} & $\mathrm{R}^{2}$ \\
\hline $\begin{array}{l}\text { Controle } \\
\text { Control }\end{array}$ & $\hat{\mathrm{Y}}=42,64 \times \mathrm{e}^{(-0,0209 \times(\mathrm{T}-3,08))+52,84}$ & 97,49 \\
$\mathrm{Na}_{2} \mathrm{~S}$ & $\hat{\mathrm{Y}}=47,78 \times \mathrm{e}^{(-0,0184 \times(\mathrm{T}-8,52))+46,51}$ & 97,26 \\
$\mathrm{NH}_{3}$ & $\hat{\mathrm{Y}}=57,35 \times \mathrm{e}^{(-0,0235 \times(\mathrm{T}-9,14))}+32,66$ & 96,40 \\
$\mathrm{Na}_{2} \mathrm{~S}+\mathrm{NH}_{3}$ & $\hat{\mathrm{Y}}=57,33 \times \mathrm{e}^{(-0,0230 \times(\mathrm{T}-5,25))}+35,08$ & 97,62 \\
\hline
\end{tabular}

$\hat{\mathrm{Y}}=\mathrm{b} \times \mathrm{e}^{(-\mathrm{c} \times(T-L)}+\mathrm{I}$, em que " $\hat{\mathrm{Y}}$ " é o resíduo no tempo $\mathrm{T} ;$ " $\mathrm{b}$ ", a fração potencialmente degradável da fibra; "c", a taxa de degradação de b; "T", o período de incubação em horas; "L", a latência; e "I", a fração indigerível da fibra.

$\hat{\mathrm{Y}}=b \times e^{(-c \times(T-L)}+I$, where "Y" is the residue in the time $T$; " $b$ ", the fraction potentially degradable of fiber;"c", rate of degradation of " $b$ "; " $T$ ", the incubation period in hours; " $L$ ", the latency; and "I", fraction indigestible of fiber.

Tabela 4 - Degradabilidade efetiva da matéria seca (DEMS), da fibra detergente neutro (DEFDN) e da fibra em detergente ácido (DEFDA) do bagaço de cana-de-açúcar não-tratado (controle) e tratado com amônia anidra $\left(\mathrm{NH}_{3}\right)$ e, ou, sulfeto de sódio $\left(\mathrm{Na}_{2} \mathrm{~S}\right)$, para as taxas de passagem de 2 e $5 \%$

Table 4 - Dry mater effective degradability (DMED) of neutral detergent fiber (NDF) and acid detergent fiber (ADF) of the sugarcane bagasse no treated (control) and treated with ammonia anhydrous $\left(\mathrm{NH}_{3}\right)$ and, or, sodium sulphide $\left(\mathrm{Na}_{2} \mathrm{~S}\right)$, for rates passage of 2 and $5 \%$

\begin{tabular}{lcccc}
\hline $\begin{array}{l}\text { Degradabilidade } \\
\text { Degradability }\end{array}$ & \multicolumn{4}{c}{$\begin{array}{c}\text { Tratamentos } \\
\text { Treatments }\end{array}$} \\
\cline { 2 - 5 } & $\begin{array}{c}\text { Controle } \\
\text { Control }\end{array}$ & $\mathrm{Na}_{2} \mathrm{~S}$ & $\mathrm{NH}_{3}$ & $\mathrm{Na}_{2} \mathrm{~S}+\mathrm{NH}_{3}$ \\
\hline $\begin{array}{l}\text { DEMS 2\% } \\
\text { DMED 2\% }\end{array}$ & 22,56 & 24,65 & 36,34 & 37,37 \\
$\begin{array}{l}\text { DEMS 5\% } \\
\text { DMED 5\% }\end{array}$ & 13,69 & 15,95 & 27,51 & 27,97 \\
$\begin{array}{l}\text { DEFDN 2\% } \\
\text { NDFED 2\% }\end{array}$ & 23,69 & 21,83 & 29,80 & 28,58 \\
$\begin{array}{l}\text { DEFDN 5\% } \\
\text { NDFED 5\% }\end{array}$ & 13,99 & 12,82 & 18,23 & 17,83 \\
$\begin{array}{l}\text { DEFDA 2\% } \\
\text { ADFED 2\% }\end{array}$ & 21,79 & 22,89 & 30,98 & 30,66 \\
$\begin{array}{l}\text { DEFDA 5\% } \\
\text { ADFED 5\% }\end{array}$ & 12,56 & 12,85 & 18,34 & 18,06 \\
\hline
\end{tabular}

$\mathrm{p}=\mathrm{a}+(\mathrm{b} \times \mathrm{c}) /(\mathrm{c}+\mathrm{k})$, em que "p" é a degradabilidade potencial; "a", a fração solúvel em água; "b", a fração insolúvel em água, mas potencialmente degradável; "c", a taxa de degradação da fração "b"; e "k", a taxa de passagem.

$p=a+(b \times c) /(c+k)$, in that " $p$ "is the potential degradability; "a", water soluble fraction;" $b$ ", water insoluble fraction, but potentially degradable; $c$ ", rate of degradation of fraction " $b$ "; and " $k$ ", the rate of passage. 
da MS, FDN e FDA foram verificados para o bagaço tratado com $\mathrm{NH}_{3}$, não havendo influência do $\mathrm{Na}_{2} \mathrm{~S}$ sobre as frações estudadas, enquanto, para a degradabilidade efetiva da MS, os resultados foram semelhantes. Para taxa de passagem de $2 \%$, os maiores valores encontrados foram de 36,34 e $37,37 \%$ para DMS, 29,80 e $28,58 \%$ para DEFDN e 30,98 e $30,66 \%$ para a DEFDA, respectivamente, para os tratamentos com $\mathrm{NH}_{3}$ e $\mathrm{NH}_{3}$ mais $\mathrm{Na}_{2} \mathrm{~S}$, enquanto o controle e o $\mathrm{Na}_{2} \mathrm{~S}$ apresentaram valores de 22,56 e 24,65\%; 23,69 e 21,83\%; e 21,79 e 22,89\%, para DMS, DEFDN e DEFDA, respectivamente.

Dessa forma, pode-se verificar que a amônia anidra aumentou a degradabilidade efetiva da MS, FDN e FDA do bagaço de cana-de-açúcar.

A degradabilidade efetiva da palha de cevada sem tratamento e tratada com uréia (6\% base MS) foi avaliada por Cañeque et al. (1998). Esses autores encontraram valores de 44,16 e 57,03\% para DEMS, de 32,71 e $46,00 \%$ para FDN e de 32,71 e $49,80 \%$ para FDA, respectivamente, para a palha não-tratada e tratada com uréia. Estes resultados reafirmam a eficiência da amonização no aumento da degradabilidade efetiva, quando foram usados restos de culturas.

\section{Conclusões}

O bagaço de cana-de-açúcar tratado com amônia anidra apresentou melhoria na degradabilidade da matéria seca, da fibra em detergente neutro e da fibra em detergente ácido.

O sulfeto de sódio não apresentou eficiência no tratamento do bagaço de cana-de-açúcar, mesmo quando associado à amônia anidra.

\section{Literatura Citada}

BEM SALEM, H.; NEFZAOUI, A.; ROKBANI, N. Upgrading of sorghum stover with anhydrous ammonia or urea treatments. Animal Feed Science and Technology, v.48, n.1/2, p.15-26, 1994.

BROWN, W.F.; PATE, F.M. Cottonseed meal or feather meal supplementation of ammoniated tropical grass hay for yearling cattle. Journal of Animal Science, v.75, p.1666-1673, 1997.

CAÑEQUE, V.; VELASCO, S., SANCHA, J.L. et al. Effect of moisture and temperature on the degradability of fiber and nitrogen fractions in barley straw treated with urea. Animal Feed Science and Technology, v.74, p.241-258, 1998.
CASTRILLO, C.; FONDEVILA, M.; GUADA, J.A. et al. Effect of ammonia treatment and carbohydrate supplementation on the intake and digestibility of barley straw diets by sheep. Animal Feed Science and Technology, v.51, p.73-90, 1995.

DJIBRILLOU, O.A.; PANDEY, V.S.; GOURO, S.A. et al. Effect of urea-treated or untreated straw with cotton seed on performances os lactating Marade (Red Sokoto) goats in Niger. Livestock Production Science, v.55, p.117-125, 1998.

FAHMY, S.T.M.; KLOPFENSTEIN, T.J. Treatment with different chemicals and their effects on the digestibility of maize stalks. 2. Intake and in vivo digestibility as affected by chemical treatment and monensin supplementation. Animal Feed Science and Technology, v.45, n.3/4, p.309-16, 1994.

GOTO, M.; YOKOE, Y. Ammoniation of barley straw. Effect on cellulose crystallinity and water-holding capacity. Animal Feed Science and Technology, v.58. p.239-247, 1996.

MERTENS, D.R. Principles of modeling and simulation in teaching and research. Journal of Dairy Science, v.60, n.7, p.1176-1186, 1976.

NEIVA, J.N.M.; GARCIA, R.; VALADARES FILHO, S.C. et al. Consumo e digestibilidade aparente de matéria seca e nutrientes em dietas à base de silagens e rolão de milho amonizados. Revista Brasileira de Zootecnia, v.27, n.3, p.453-460, 1998.

ØRSKOV, E.R.; McDONALD, I. The estimation of protein degradability in the rumen from incubation measurements weighted according to rate of passage. Journal of Agriculture Science, v.92, p.449-53, 1979.

PAIVA, J.A.J.; GARCIA, R.; QUEIROZ, A.C. et al. Efeitos dos diferentes níveis de amônia anidra e períodos de amonização sobre a degradabilidade da matéria seca e de constituintes da parede celular da palhada de milho (Zea mays L.). Revista Brasileira de Zootecnia, v.24, n.5, p.693-705, 1995.

RAHAL, A.; SINGH, A.; SINGH, M. Effect of urea treatment and composition on, and prediction of value of rice straw of different cultivars. Animal Feed Science and Technology, v.68, p.165-182, 1997.

SARMENTO, P.; GARCIA, R.; PIRES, A.J.V. et al. Tratamento do bagaço de cana-de-açúcar com uréia. Revista Brasileira de Zootecnia, v.28, n.6, p.1203-1208, 1999.

SILVA, D.J. Análise de alimentos: métodos químicos e biológicos. Viçosa, MG: Universidade Federal de Viçosa, 1990. 165p.

SOUZA, A.L.; GARCIA, R.; PEREIRA, O.G. et al. Composição químico-bromatológica da casca de café tratada com amônia anidra e sulfeto de sódio. Revista Brasileira de Zootecnia, v.30, n.3, p.983-991, 2001.
Recebido em: 20/05/02 Aceito em: 10/11/03 